\title{
Application of artificial neural networks to approximation and identification of sea-keeping performance of a bulk carrier in ballast loading condition
}

\author{
Tomasz Cepowski \\ Szczecin Maritime University
}

\section{ABSTRACT}

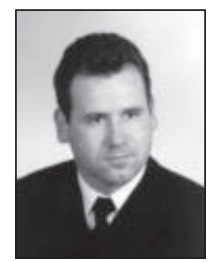

This paper presents an application of artificial neural networks to approximation and identification of additional wave-generated resistance, slamming and internal forces depending on ship motion and wave parameters. The analysis was performed for a typical bulk carrier in ballast loading conditions. The investigations were carried out on the basis of ship response data calculated by means of exact numerical methods. Analytical functions presented in the form of artificial neural networks were analyzed with a view of their accuracy against standard values. Possible ways of application of the artificial neural networks were examined from the point of view of accuracy of approximation and identification of the assumed ship response parameters.

Keywords : ship, ship sea keeping qualities, artificial neural networks, slamming, additional wave generated resistance, internal forces, shear forces, bending moments, wave parameters, approximation, identification, assessment

\section{INTRODUCTION}

Various optimization methods of ship design parameters or operational ones are often applied to problems associated with ship designing and operation. Economic profits are the main criteria for which target functions are usually formulated. And, ship sea-keeping qualities are usually used as constraints for ship design or shipping route since they first of all influence ship safety. To this end various approaches are applied. In the publications $[1,4]$ assessment of sea-keeping qualities was presented in terms of the operational effectiveness index $\mathrm{E}_{\mathrm{T}}$, which expresses probability of the event that ship response to given wave conditions will not exceed an assumed level:

$$
\mathrm{E}_{\mathrm{T}}=\sum_{\mathrm{A}} \sum_{\mathrm{S}} \sum_{\mu} \sum_{\mathrm{HT}} \sum_{\mathrm{V}} \sum_{\psi}[\mathrm{P}(\Omega=1)]
$$
where:

$\mathrm{E}_{\mathrm{T}}$ - the operational effectiveness index under assumptions that:

- Ship will operate in a given sea region with the frequency $f_{A}$

- It will operate in that region with the frequency $f_{S}$ in each season of the year

- In a given season and sea region waves of $\mathrm{f}_{\mu}$ frequency propagating from $\mu$ directio, will occur

- For $\mu$-direction waves of the parameters $\mathrm{H}_{\mathrm{S}}$ (significant height) and $\mathrm{T}$ (significant period) will occur with the frequency $\mathrm{f}_{\mathrm{HT}}$

- On its shipping route the considered ship will move with the speed $\mathrm{V}$ and course angle $\psi$ with the frequencies $\mathrm{f}_{\mathrm{v}}$ and $\mathrm{f}_{\psi}$, respectively
- Permissible criterion values assumed for selected seakeeping qualities will not be exceeded.

$\Omega-$ a function which usually takes the values:

0 - in the case when ship response exceeds its permissible criterion value

1 - in the case when ship response does not exceed its permissible criterion value

$\mathrm{P}-$ probability of the event that the function $\Omega$ will take the value equal to 1 for given wave and ship motion parameters.

In Eq. 1 a crucial element is the function $\Omega$ which makes it possible to assess sea-keeping qualities quantitatively. In Fig. 1 the classical algorithm for determining the function $\Omega$ is presented (algorithm no 1). In the first phase, values of sea-keeping qualities are calculated by using exact numerical methods or approximating functions. In the second phase, values of the function $\Omega$ are determined on the basis of the criteria for the sea-keeping qualities.

\begin{tabular}{|c|c|c|c|c|}
\hline $\begin{array}{c}\text { Input } \\
\text { parameters }\end{array}$ & Prediction & \begin{tabular}{|c|} 
Sea-keeping \\
qualities
\end{tabular} & Assesment & $\begin{array}{c}\text { Function } \\
\Omega\end{array}$ \\
\hline
\end{tabular}

Fig. 1. Algorithm no. 1 for determining the function $\Omega$

In this work another approach is proposed, namely that based on using only one phase for direct determining the function $\Omega$ instead of two (prediction and assessment). The algorithm described further as the algorithm no. 2 , is presented in Fig. 2. The artificial neural networks are there applied to identify values of the function $\Omega$. 


\begin{tabular}{|c|c|c|}
\hline Input \\
parameters
\end{tabular} Identification $>\begin{gathered}\text { Function } \\
\Omega\end{gathered}$

Fig. 2. An alternative algorithm for determining the function $\Omega$

In this work a comparative analysis of both the approaches is performed, i.e.:

+ Prediction (approximation) of sea-keeping qualities

+ Identification of sea-keeping qualities (values of the function $\Omega$ ).

\section{Assumptions}

The investigations were performed for B-517 bulk carrier of the following particulars:

- Overall length: $\mathrm{Lc}=198 \mathrm{~m}$

Length between perpendiculars: Lpp $=185 \mathrm{~m}$

Breadth: $\mathrm{B}=24.4 \mathrm{~m}$

Design draught: $\mathrm{T}=11 \mathrm{~m}$

- Block coefficient of immersed part of ship hull: $\mathrm{C}_{\mathrm{B}}=0.82$

Water-plane coefficient: $\mathrm{C}_{\mathrm{wL}}=0.87$.

The ship's hull form is presented in Fig. 3.
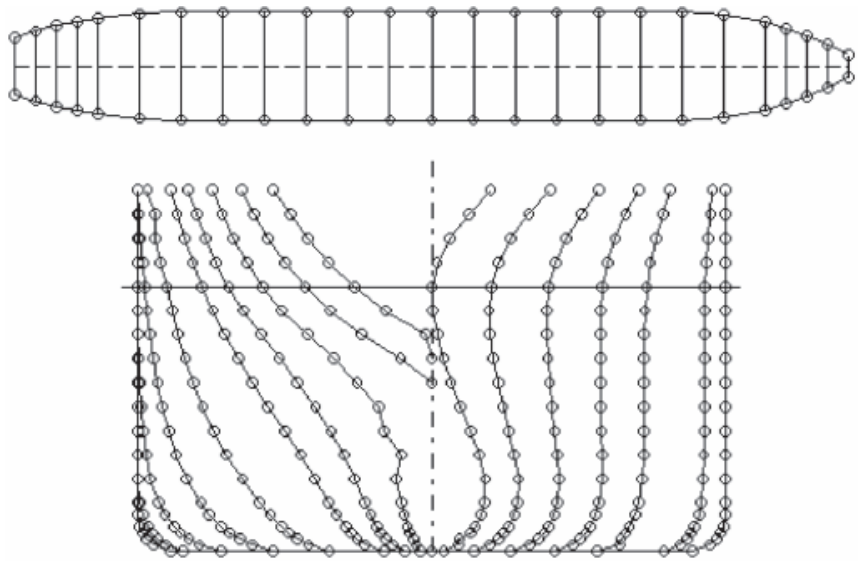

Fig. 3. Body lines of B-517 bulk carrier

The following ballast loading condition was taken into consideration:

* mass of ballast: $1830 \mathrm{t}$

* mass of stores: $1240 \mathrm{t}$ (50\% of full mass of stores).

At this loading condition the ship obtained the following stability parameters:

Displacement: $\mathrm{D}=18069 \mathrm{t}$

Average draught: $\mathrm{Tm}=4.79 \mathrm{~m}$

$>$ Trim: $\mathrm{t}=-1.15 \mathrm{~m}$

$>$ Initial transverse metacentric height: $\mathrm{GM}=3.27 \mathrm{~m}$

$>$ Propeller immersion ratio: $\operatorname{Pr}=150 \%$.

In Fig. 4 the ship's curve of weights is presented for the analyzed loading condition.

In the investigations were taken into account the sea-keeping qualities which influence ship safety most detrimentally. In the general case of transport ship to such qualities the following belong acc. [1, 4]: rolling. slamming, green water shipping on the deck, propeller emerging, vertical accelerations on the bridge and bow. And, only slamming is of importance for the considered bulk carrier in the assumed load condition (in view of the values of trim, transverse metacentric height and propeller immersion ratio).
Moreover, structural safety problems associated with longitudinal strength can appear on the bulk carriers of the kind. Therefore in the analysis:

slamming and

$>$ internal forces (bending moments and shear forces at selected frame stations) were taken into consideration.

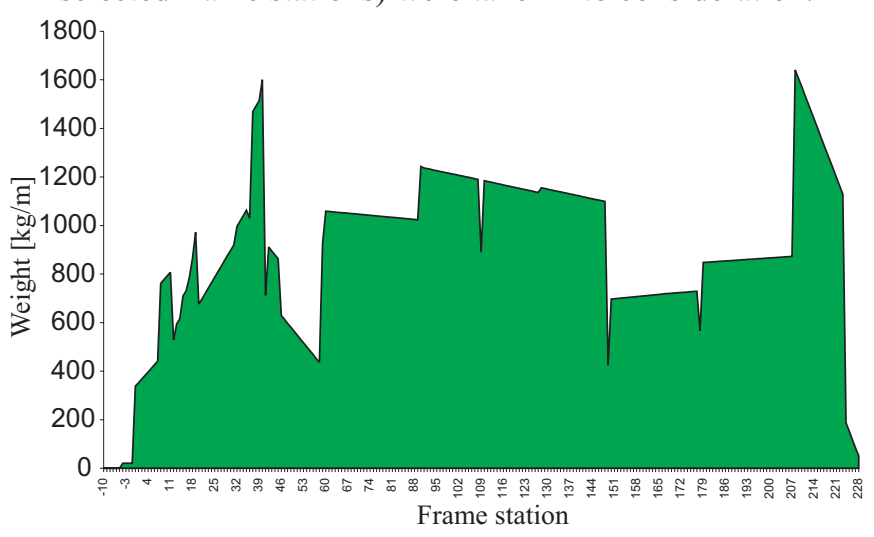

Fig. 4. Curve of weights for B-517 bulk carrier in the ballast loading condition and $50 \%$ amount of stores

Additionally it was decided to analyze possible application of artificial neural networks to approximation and identification of additional ship resistance to motion in waves.

In the investigations the following operational parameters of the ship were taken into account:

$\Rightarrow$ the ship's speed $\mathrm{V}$ ranging from 0 to 15 knots, every 5 knots

$\Rightarrow$ the wave encounter angle $\Omega=0^{\circ}$ (following waves), $15^{\circ}$, $30^{\circ}, 60^{\circ}, 75^{\circ}, 90^{\circ}, 105^{\circ}, 120^{\circ}, 150^{\circ} 175^{\circ}, 180^{\circ}$ (heading waves)

$\Rightarrow$ the significant wave height $\mathrm{H}_{\mathrm{s}}$ ranging from 1 to $9 \mathrm{~m}$, every second $\mathrm{m}$

$\Rightarrow$ the characteristic wave period $\mathrm{T}_{\mathrm{s}}=6 \div 20 \mathrm{~s}$, every second $\mathrm{s}$.

Model (reference) values for approximation were calculated with the use of SEAWAY software based on exact numerical methods.

The SEAWAY software utilizes the two-dimensional flow theory and calculates ship motions in regular and irregular waves. Tests of accuracy of the software, presented in [2,3], show high accuracy of its calculation results.

\section{APPROXIMATION AND IDENTIFICATION OF SEA-KEEPING QUALITIES BY MEANS OF ARTIFICIAL NEURAL NETWORKS}

The functions $\psi$ which serve for approximation and identification of ship's response, can be found in accordance with the following formula:

$$
\mathrm{X} \stackrel{\Psi}{\longrightarrow} \mathrm{Y}
$$

where:

$X$ - set of assumed (input) operational parameters

$\mathrm{Y}$ - set of response(output) values calculated with the use of exact methods

$\Psi$ - searched-for analytical function in the form of an artificial neural network, serving for approximation or identification of ship's response.

The phase of searching for the best network was composed of the following steps:

- determination of the best structure of the network by using genetic algorithms

$\rightarrow$ teaching the network 
$\rightarrow$ testing the network

accuracy assessment of the network's approximation on the basis of the testing results.

For teaching the neural networks $50 \%$ of all the data at most were utilized so as not to cause the over-teaching of the network.

For the approximation accuracy assessment were used teaching and testing errors which can be determined in accordance with Eq. (3):

$$
\mathrm{RMS}=\sqrt{\frac{\left(\Psi_{\mathrm{w}}-\Psi\right)^{2}}{\mathrm{n}}}
$$

where:

RMS - error value

$\Psi_{\mathrm{w}} \quad-$ model values used for teaching or testing the neural network

$\Psi \quad-$ values calculated by using the neural network

$\mathrm{n} \quad-$ number of records.

The neural networks elaborated

for approximation and identification of:

- additional wave- generated resistance

- internal forces

- slamming

are presented below.

The neural networks were elaborated with the use of the software STATISTICA Neural Networks.

\section{Additional wave-generated resistance}

\section{Approximation}

The best network approximating additional wave-generated resistance appeared a MLP network of 4x7x1 structure (Fig. 5) characterized by:

A the high value of the correlation coefficient $\mathrm{R}=0.95$

1 the value of RMS teaching error $=48 \mathrm{kN}$

A the value of RMS validation error $=54 \mathrm{kN}$

A the value of RMS testing error $=52 \mathrm{kN}$.

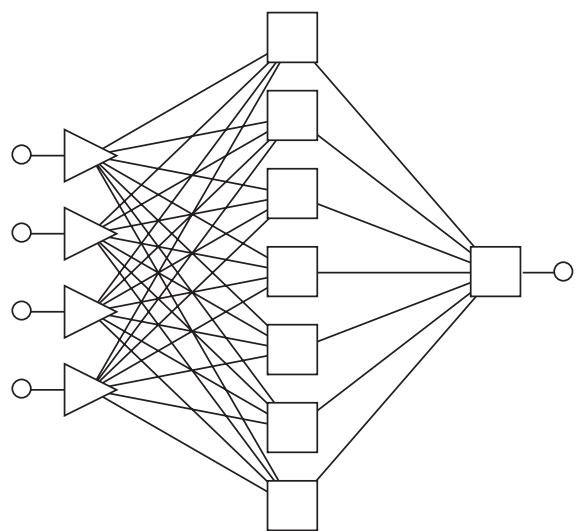

Fig. 5. Schematic diagram of the MLP artificial neural network of $4 x 7 x 1$ structure for approximation of additional wave-generated resistance of B-517 bulk carrier in ballast loading condition

The searched-for function approximating the additional wave-generated resistance $\mathrm{R}$, elaborated by means of the above mentioned neural network, is presented in the analytical form of Eq. (4):

$$
\mathrm{R}=\frac{\left(\frac{1}{\left.1+\mathrm{e}^{\left.-\left(\left[\beta, \mathrm{V}, \mathrm{Hs}, \mathrm{T}_{\mathrm{S}}\right] \times \mathrm{S}+\mathrm{P}\right) \times \mathrm{A}-\mathrm{B}\right)} \times \mathrm{C}-\alpha_{0}\right)-\alpha_{1}}\right.}{\alpha_{2}}
$$

where:

$\mathrm{R}$ - additional wave-generated resistance [kN]

$\mathrm{V}$ - ship speed [kn]

$\beta-$ wave encounter angle [deg]

$\mathrm{T}_{\mathrm{S}}-$ characteristic wave period $[\mathrm{s}]$

$\mathrm{H}_{\mathrm{S}}-$ significant wave height $[\mathrm{m}]$

\section{A - matrix of weighting values}

$\begin{array}{ccccccc}3.061 & 3.060 & -9.035 & -8.150 & 5.422 & 0.389 & -7.598 \\ 0.985 & 1.097 & 0.878 & 0.772 & 0.452 & 3.646 & 0.721 \\ 1.774 & 2.427 & 0.651 & 1.253 & -0.847 & -1.871 & 2.031 \\ -6.194 & -4.738 & 1.153 & 0.450 & 0.498 & 1.449 & -0.269\end{array}$

B - vector of threshold values:

$\left[\begin{array}{lllllll}6.082 & 5.747 & -2.717 & -2.682 & 2.524 & -3.422 & -2.742\end{array}\right]$

$\mathrm{C}$ - column vector of weighting values:

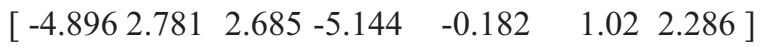

$\mathrm{S}$ - matrix of coefficients:

$\left|\begin{array}{cccc}0.0056 & 0 & 0 & 0 \\ 0 & 0.067 & 0 & 0 \\ 0 & 0 & 0.1250 & 0 \\ 0 & 0 & 0 & 0.0714\end{array}\right|$

P - vector of displacement values:

$$
\left[\begin{array}{llll}
0 & 0 & -0.1250 & -0.4286
\end{array}\right]
$$

$\alpha_{0}, \alpha_{1}, \alpha_{2}-$ coefficients of the following values:

$$
\alpha_{0}=0.454, \alpha_{1}=0.3749, \alpha_{2}=0.0005
$$

Fig. 6 presents comparison of the approximation of the additional wave-generated resistance calculated from Eq. (4) with the values calculated by using the exact methods included in the SEAWAY software. For the test was assumed the ship's speed being beyond the speed range taken into account during modelling the neural network and described by Eq. (4). From the comparison it results that the function described by Eq. (4) is characterized by a relatively high extrapolating accuracy within that range of wave and ship motion parameters.

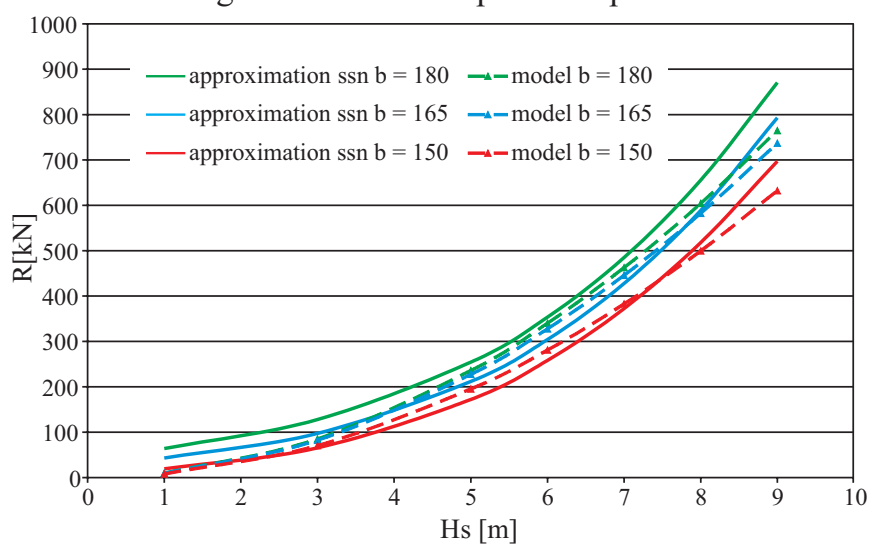

Fig. 6. Approximation of the additional wave-generated resistance $R$, $V=20$ knots, $T s=14 \mathrm{~s}, H s=$ var, $b=$ var

\section{Identification}

In this part of investigations were elaborated the artificial neural networks which make it possible to identify the additional wave-generated resistance expressed in the form of the four-state nominal function $\Omega_{\mathrm{R}}$ equal to:

is $\mathrm{R}_{1}$ - thrust (for the additional wave-generated resistance $\mathrm{R}<0 \mathrm{kN}$ ) 
is $\mathrm{R}_{2}$ - lack of the resistance (for values of $\mathrm{R}=0 \div 30 \mathrm{kN}$ )

is $\mathrm{R}_{3}-$ a small value of the resistance (for values of $\mathrm{R}=30 \div 100 \mathrm{kN}$ )

$\star R_{4}$ - a large value of the resistance (for values of $R$ exceeding $100 \mathrm{kN}$ ).

The best artificial neural network which made it possible to identify the additional wave-generated resistance appeared to be the MLP network of 4x15x4x1 structure, characterized by the statistics shown in Tab. 1 .

Tab.1. Statistics applied to classification problems of the artificial neural network identifying the additional wave-generated resistance of B-517 bulk carrier in ballast loading condition

\begin{tabular}{|c|c|c|c|c|c|c|c|c|c|c|c|c|}
\hline \multirow{2}{*}{$\begin{array}{l}\text { Number of } \\
\text { events }\end{array}$} & \multicolumn{4}{|c|}{ Teaching set } & \multicolumn{4}{|c|}{ Validating set } & \multicolumn{4}{|c|}{ Testing set } \\
\hline & R1 & $\mathrm{R} 2$ & R3 & R4 & $\mathrm{R} 1$ & $\mathrm{R} 2$ & R3 & R4 & R1 & $\mathrm{R} 2$ & R3 & R4 \\
\hline Total & 124 & 541 & 182 & 253 & 83 & 354 & 106 & 139 & 73 & 340 & 109 & 160 \\
\hline Correct & 124 & 536 & 161 & 235 & 83 & 352 & 93 & 133 & 73 & 337 & 98 & 151 \\
\hline Erronous & 0 & 5 & 21 & 18 & 0 & 2 & 13 & 6 & 0 & 3 & 11 & 9 \\
\hline Indeterminate & 0 & 0 & 0 & 0 & 0 & 0 & 0 & 0 & 0 & 0 & 0 & 0 \\
\hline
\end{tabular}

The above mentioned artificial neural network can be analytically presented by means of Eq. (5) and (6):

$$
\Omega_{\mathrm{R}}=\left\{\begin{array}{l}
\mathrm{R}_{1} \Leftrightarrow \alpha_{1}=1 \\
\mathrm{R}_{2} \Leftrightarrow \alpha_{2}=1 \\
\mathrm{R}_{3} \Leftrightarrow \alpha_{3}=1 \\
\mathrm{R}_{4} \Leftrightarrow \alpha_{4}=1
\end{array}\right.
$$

where:

$\Omega_{\mathrm{R}} \quad$ - additional wave - generated resistance in the form of the four-state nominal variable: $\mathrm{R}_{1}-$ resistance thrust, $\mathrm{R}_{2}$ - lack of resistance, $\mathrm{R}_{3}$ - small resistance, $\mathrm{R}_{4}-$ large resistance

$\alpha_{1}, \alpha_{2}, \alpha_{3}, \alpha_{4}-$ initial values of the artificial neural network, determined on the last- but- one layer, calculated from Eq. (6):

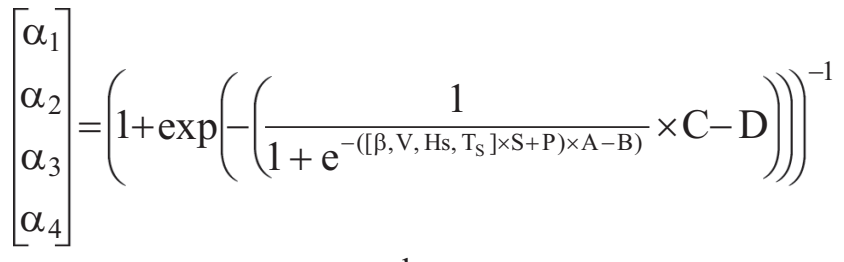

where:

$\mathrm{V}-$ ship's speed [kts]

$\beta-$ wave encounter angle $[\mathrm{deg}]$

$\mathrm{T}_{\mathrm{S}}-$ characteristic wave period $[\mathrm{s}]$

$\mathrm{H}_{\mathrm{S}}-$ significant wave height $[\mathrm{m}]$.

\section{A - matrix of weighting values:}

\begin{tabular}{|cccccccccccccc|c|}
-4.8 & 10.8 & -4.3 & 13.8 & -10.9 & -9.7 & 11.1 & -35.8 & 8.1 & -27.9 & -2.7 & -8.2 & -24.4 & 24.5 & -4.0 \\
-1.9 & -11.0 & -2.5 & 25.4 & -5.2 & -3.7 & 14.6 & 1.6 & -9.1 & -41.8 & -7.4 & 2.6 & -2.9 & -5.0 & -7.9 \\
-6.3 & -20.5 & 2.2 & -0.6 & -16.9 & 19.0 & -3.8 & -1.9 & 11.2 & -0.9 & -3.9 & -4.9 & -7.8 & -2.7 & -1.6 \\
7.4 & 16.0 & 8.4 & 1.6 & 14.9 & 9.7 & 2.2 & 4.2 & -6.2 & 1.4 & -2.6 & -23.2 & 11.6 & 11.8 & 1.3
\end{tabular}

$B$ - vector of threshold values:

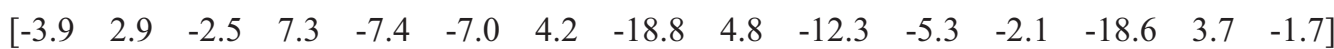

\begin{tabular}{|c|c|c|c|c|c|c|c|c|c|c|c|c|c|}
\hline 0.9 & -0.8 & -14.2 & -0.3 & -2.2 & -5.5 & 5.5 & 3.6 & 16.5 & 4.6 & 2.7 & -1.0 & -2.5 & 4.3 \\
\hline-5.5 & -5.8 & 7.2 & 18.2 & -12.2 & -13.9 & 22.5 & 2.6 & -45.6 & 1.5 & 16.3 & -7.1 & 14.4 & -3.2 \\
\hline 18.8 & -1.8 & -16.3 & -27.3 & 12.9 & 5.0 & -7.8 & -1.9 & -9.5 & -4.4 & -7.6 & 15.7 & -5.6 & -5.4 \\
\hline-15.1 & 11.5 & -3.9 & -5.8 & 25.5 & 0.9 & -23.9 & -3.9 & -4.1 & 3.8 & -5.3 & -8.3 & -17.4 & 0.7 \\
\hline
\end{tabular}

\section{C - matrix of weighting values:}

D - column vector of weighting values:

$\left[\begin{array}{llll}4.5 & 3.1 & 3.1 & -0.9\end{array}\right]$

$\mathrm{S}$ - matrix of coefficients having the same values as in Eq. (4)

$\mathrm{P}$ - vector of displacements having the same values as in Eq. (4). 


\section{Slamming \\ Appproximation}

The best network approximating occurrence probability of slamming appeared MLP network of $4 \times 2 \times 1$ structure, characterized by:

the correlation coefficient $\mathrm{R}=0.9$

the RMS teaching error $=0.95 \%$

the RMS validation error $=0.76 \%$

the RMS testing error $=0.96 \%$.

The searched-for function approximating the occurrence probability of slamming, $\mathrm{P}_{\mathrm{S}}$, elaborated by means of the above mentioned neural network, is analytically presented in the form of Eq. (7):

$$
\mathrm{P}_{\mathrm{S}}=\frac{\left(\frac{1}{\left.1+\mathrm{e}^{\left.-\left(\left[\beta, \mathrm{V}, \mathrm{Hs}, \mathrm{T}_{\mathrm{S}}\right] \times \mathrm{S}+\mathrm{P}\right) \times \mathrm{A}-\mathrm{B}\right)} \times \mathrm{C}-\alpha_{0}\right)}\right.}{\alpha_{1}}
$$

where:

$\mathrm{P}_{\mathrm{S}}-$ slamming occurrence probability [\%],

$\mathrm{V}$ - ship's speed [kn]

$\beta-\quad$ wave encounter angle $[\mathrm{deg}]$

$\mathrm{T}_{\mathrm{S}}-$ characteristic wave period $[\mathrm{s}]$

$\mathrm{H}_{\mathrm{S}}-$ significant wave height $[\mathrm{m}]$

\section{A - matrix of weighting values:}

$\left|\begin{array}{cc}5.628 & 6.929 \\ 2.297 & 2.483 \\ 6.812 & 6.551 \\ -8.117 & -13.530\end{array}\right|$

\section{B - vector of threshold values:}

$\left[\begin{array}{ll}12.929 & 14.016\end{array}\right]$

\section{$\mathrm{C}$ - vector of weighting values:}

$\left[\begin{array}{ll}4.7 & -4.249\end{array}\right]$

$\mathrm{S}$ - matrix of coefficients having the same values as in Eq. (4)

$\mathrm{P}$ - vector of displacements having the same values as in Eq. (4).

$\alpha_{0}, \alpha_{1}, \alpha_{2}-$ coefficients having the values as follows:

$$
\alpha_{0}=0,0032, \alpha_{1}=0,0476 .
$$

In Fig. 7 is presented extrapolation of the slamming occurrence probability $\mathrm{P}_{S}$ calculated from Eq. (7) compared with the values calculated by using the exact method implemented in the SEAWAY software. From the comparison it results that the function described by Eq. (7) is characterized by a relatively high accuracy as far as extrapolation is concerned.

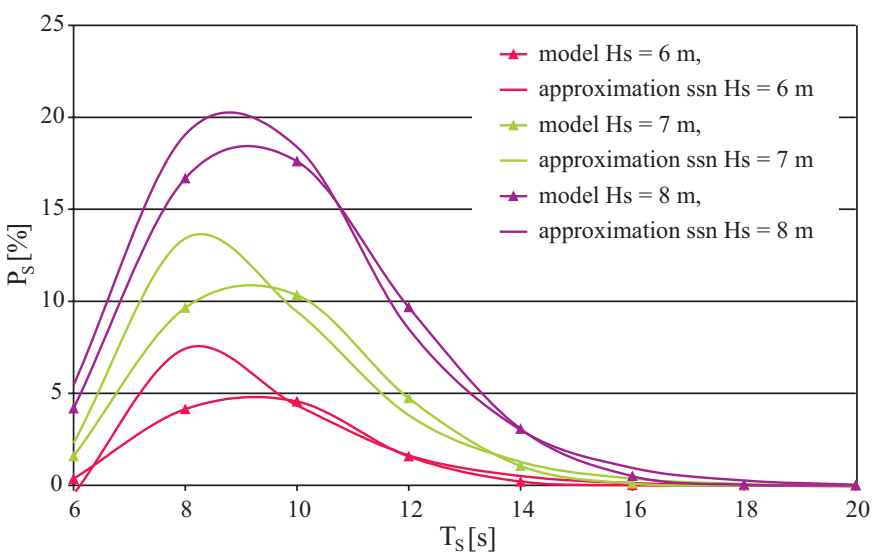

Fig. 7. Approximation of the slamming occurrence probability $P_{S}, V=20$ knots, $b=165^{\circ},\left[T_{S}, H_{s}\right]=$ var

\section{Identification}

In this part of the investigations was elaborated the artificial neural network which makes it possible to assess occurrence of slamming in the form of the two-state nominal variable $\Omega_{\mathrm{s}}$ taking the values:

- „0" - if slamming value does not exceed a dangerous threshold (not greater than 3\%)

- „1" - if slamming value exceeds a dangerous threshold (greater than 3\%).

The best artificial neural network which made it possible to identify values of the function $\Omega_{\mathrm{S}}$ appeared to be the MLP network of $4 \times 18 \times 1$ structure, characterized by the statistics shown in Tab. 2.

Tab.2. Statistics applied to classification problems of the artificial neural network identifying values of the function $\Gamma_{\text {s }}$ for $B-517$ bulk carrier in ballast loading condition

\begin{tabular}{|c|c|c|c|c|c|c|}
\hline \multirow{2}{*}{$\begin{array}{c}\text { Number } \\
\text { of events }\end{array}$} & \multicolumn{2}{|c|}{ Teaching set } & \multicolumn{2}{c|}{$\begin{array}{c}\text { Validating } \\
\text { set }\end{array}$} & \multicolumn{2}{c|}{ Testing set } \\
\cline { 2 - 7 } & $\mathbf{\Omega}_{\mathrm{s}}=\mathbf{0}$ & $\mathbf{\Omega}_{\mathrm{s}}=\mathbf{1}$ & $\mathbf{\Omega}_{\mathrm{s}}=\mathbf{0}$ & $\mathbf{\Omega}_{\mathrm{s}}=\mathbf{1}$ & $\mathbf{\Omega}_{\mathrm{s}}=\mathbf{0}$ & $\mathbf{\Omega}_{\mathrm{s}}=\mathbf{1}$ \\
\hline Total & 53 & 1047 & 34 & 648 & 27 & 655 \\
\hline Correct & 51 & 1029 & 34 & 641 & 27 & 638 \\
\hline Erronous & 2 & 18 & 0 & 7 & 0 & 17 \\
\hline Indeterminate & 0 & 0 & 0 & 0 & 0 & 0 \\
\hline
\end{tabular}

The above mentioned artificial neural network can be analytically presented by means of Eq. (8):

$$
\Omega_{\mathrm{S}}=\left(1+\exp \left(-\left(\frac{1}{1+\mathrm{e}^{\left.-\left(\left[\beta, \mathrm{V}, \mathrm{Hs}, \mathrm{T}_{\mathrm{S}}\right] \times \mathrm{S}+\mathrm{P}\right) \times \mathrm{A}-\mathrm{B}\right)}} \times \mathrm{C}-1\right)\right)\right)^{-1}
$$

where:

$\Omega_{\mathrm{S}}$ - slamming in the form of the two-state nominal variable: „0" - slamming not exceeding a permissible value, „1" - slamming exceeding a permissible value; V - ship's speed [knots]; $\beta$ - wave encounter angle [deg];

\begin{tabular}{|c|c|c|c|c|c|c|c|c|c|c|c|c|c|c|c|c|c|}
\hline & 09 & 04 & & & 98 & & & & & & & & & & & & \\
\hline & 4 & & 64 & م 0 & 49 & & & & & & & & & & & & \\
\hline & - & .1 & .02 & -9.46 & & & & & & & & & & & & & \\
\hline & 6.37 & .11 & .16 & 14.80 & 5.77 & 6.75 & .97 & 3.34 & 5.12 & 10.65 & & 5.55 & 10.66 & -0.01 & 0.38 & -1.84 & \\
\hline
\end{tabular}

$\mathrm{T}_{\mathrm{S}}-$ characteristic wave period $[\mathrm{s}] ; \mathrm{H}_{\mathrm{S}}-$ significant wave height $[\mathrm{m}]$

\section{A - matrix of weighting values:}




\section{B - vector of threshold values:}

$\left[\begin{array}{llllllll}0.65 & 5.60 & -4.12 & 0.65 & -8.81 & 10.51 & 1.37 & 0.23\end{array}\right.$

$\begin{array}{lllllll}1.06 & 2.82 & -13.07 & -10.73 & -0.11 & -4.74 & 2.39\end{array}$

$-5.11-1.25-0.88]$

\section{C - column vector of weighting values:}

$\left[\begin{array}{lllllll}-2.91 & -9.63 & 11.63 & -4.31 & 23.06 & -27.36 & -9.65\end{array}\right.$

$\begin{array}{llllllll}-3.31 & 1.27 & 2.64 & 23.11 & 15.06 & -5.59 & 20.2 & -3.78\end{array}$ $16.21 \quad 5 \quad 1.18]$

$\mathrm{S}$ - matrix of coefficients having the same values as in Eq. (4)

$\mathrm{P}$ - vector of displacements having the same values as in Eq. (4).

\section{Internal forces}

In the investigations were taken into consideration shear forces and bending moments for B 517 bulk carrier in irregular waves, occurring at frame stations where an appropriate longitudinal strength of the ship in still water is required.

\section{Approximation}

For the approximation of shear forces and bending moments in irregular waves at selected frame stations of the ship was used the set of MLP neural networks having the structures and statistical parameters shown in Tab. 3 and 4.

Tab.3. Structure and statistics of artificial neural networks approximating, at selected frame stations, shear forces of B-517 bulk carrier in ballast loading condition

\begin{tabular}{|c|c|c|c|c|}
\hline $\begin{array}{c}\text { Frame } \\
\text { stations }\end{array}$ & $\begin{array}{c}\text { Distance } \\
\text { from } \\
\text { A.P. }[\mathbf{m}]\end{array}$ & $\begin{array}{c}\text { Structure } \\
\text { of } \\
\text { network }\end{array}$ & $\begin{array}{c}\text { Coefficient } \\
\text { of } \\
\text { correlation } \\
\text { R }\end{array}$ & $\begin{array}{c}\text { RMS } \\
\text { validation } \\
\text { error }[\mathbf{k N}]\end{array}$ \\
\hline 41 & 33.21 & $4 \times 7 \times 1$ & 0.98 & 427.8 \\
\hline 59 & 49.41 & $3 \times 12 \times 1$ & 0.98 & 623.3 \\
\hline 90 & 77.31 & $4 \times 15 \times 1$ & 0.98 & 484.4 \\
\hline 109 & 94.41 & $4 \times 6 \times 1$ & 0.97 & 496.9 \\
\hline 128 & 111.51 & $4 \times 11 \times 1$ & 0.99 & 374.0 \\
\hline 149 & 130.41 & $4 \times 9 \times 1$ & 0.98 & 692.0 \\
\hline 178 & 154.51 & $4 \times 4 \times 1$ & 0.96 & 1143.4 \\
\hline 208 & 175.51 & $4 \times 6 \times 1$ & 0.97 & 358.5 \\
\hline
\end{tabular}

Tab.4. Structure and statistics of artificial neural networks approximating, at selected frame stations, bending moments of B-517 bulk carrier in ballast loading condition

\begin{tabular}{|c|c|c|c|c|}
\hline $\begin{array}{c}\text { Frame } \\
\text { stations }\end{array}$ & $\begin{array}{c}\text { Distance } \\
\text { from } \\
\text { A.P. }[\mathbf{m}]\end{array}$ & $\begin{array}{c}\text { Structure } \\
\text { of } \\
\text { network }\end{array}$ & $\begin{array}{c}\text { Coefficient } \\
\text { of } \\
\text { correlation } \\
\mathbf{R}\end{array}$ & $\begin{array}{c}\text { RMS } \\
\text { validation } \\
\text { error }[\mathbf{k N}]\end{array}$ \\
\hline 41 & 33.21 & $4 \times 9 \times 1$ & 0.97 & 6460.3 \\
\hline 59 & 49.41 & $4 \times 11 \times 1$ & 0.98 & 13681.1 \\
\hline 90 & 77.31 & $4 \times 7 \times 1$ & 0.98 & 28725.3 \\
\hline 109 & 94.41 & $4 \times 8 \times 1$ & 0.98 & 27335.0 \\
\hline 128 & 111.51 & $4 \times 6 \times 1$ & 0.98 & 30878.2 \\
\hline 149 & 130.41 & $4 \times 8 \times 1$ & 0.98 & 31132.8 \\
\hline 178 & 154.51 & $4 \times 15 \times 1$ & 0.97 & 12484.2 \\
\hline 208 & 175.51 & $4 \times 15 \times 1$ & 0.96 & 2236.0 \\
\hline
\end{tabular}

In Fig. 8 through 11 are presented extrapolations of shear forces and bending moments obtained by means of the artificial neural networks, compared with values calculated with the use of the exact methods implemented in the SEAWAY software. From the tables it results that the above mentioned extrapolations are characterized by a relatively high accuracy.
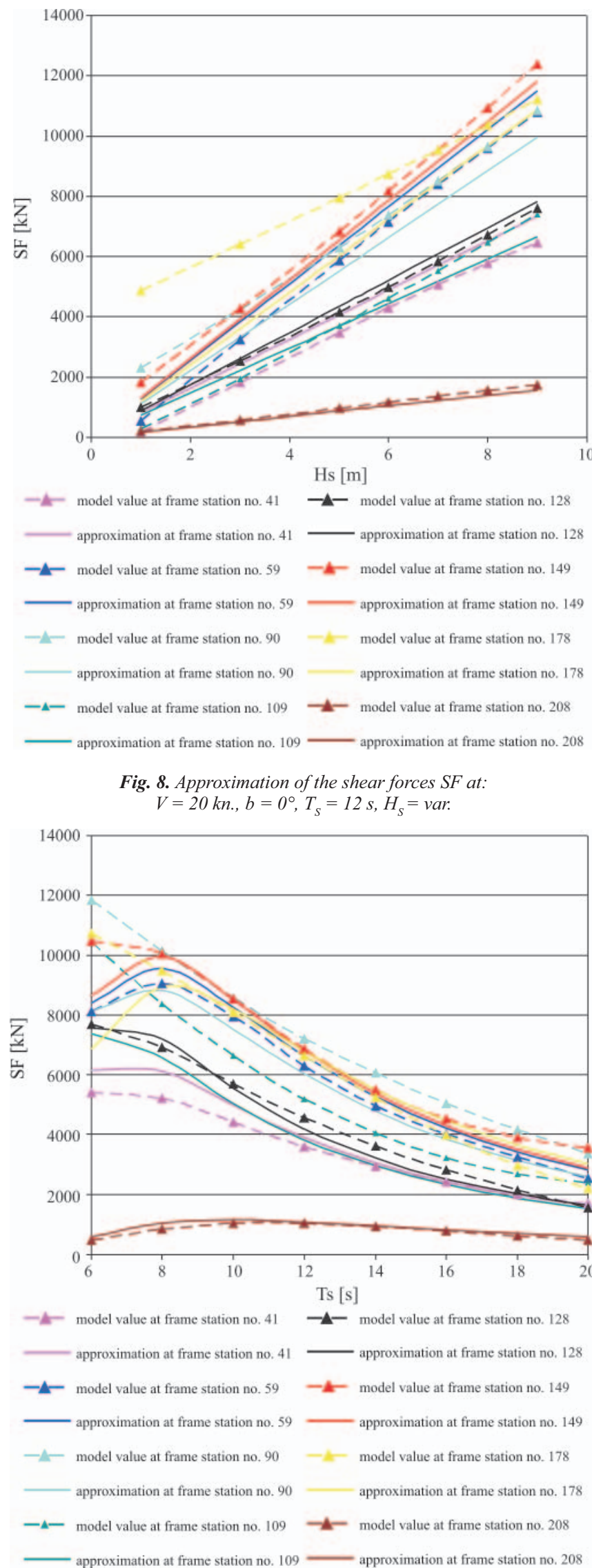

Fig. 9. Approximation of the shear forces $S F$ at: $V=20 \mathrm{kn} ., \mathrm{b}=0^{\circ}, H_{S}=6 \mathrm{~m}, T_{\mathrm{S}}=v a r$ 


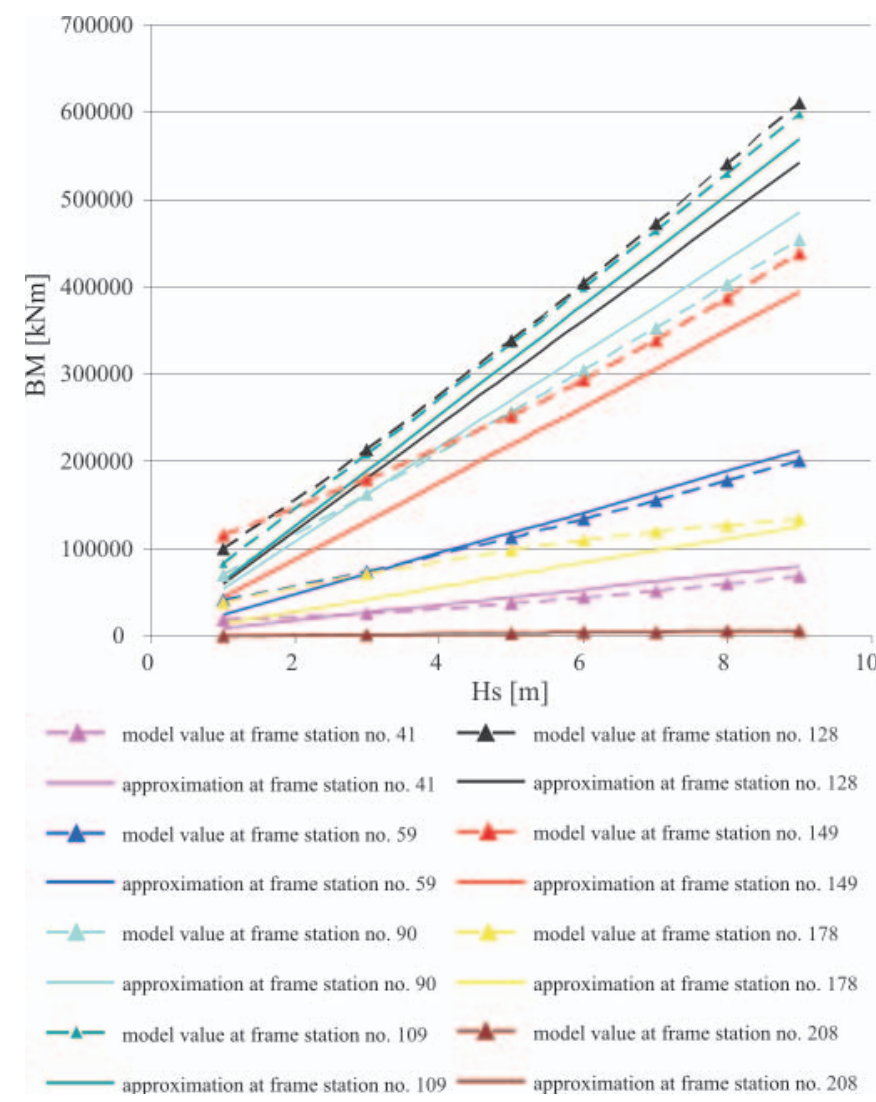

Fig. 10. Approximation of the bending moments BMat: $V=20 \mathrm{kn} ., b=0^{\circ}, T_{s}=12 \mathrm{~s}, H_{\mathrm{S}}=$ var.

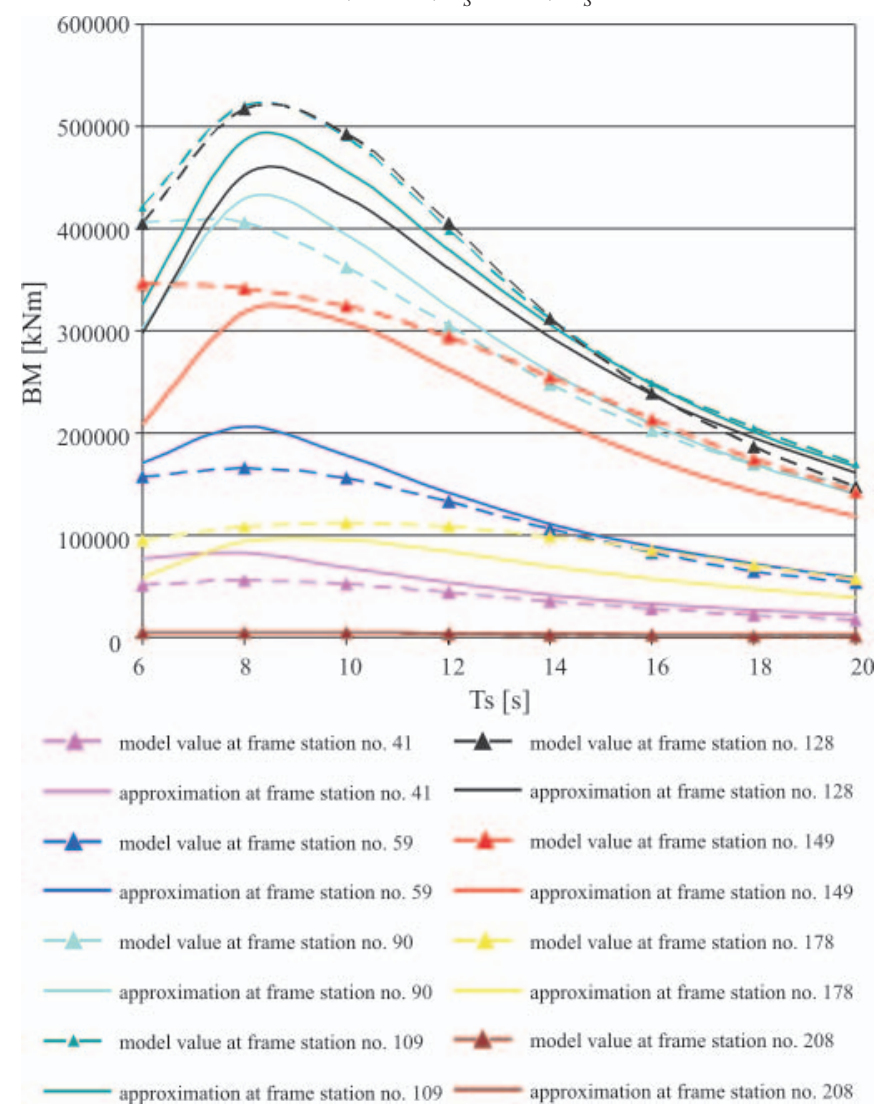

Fig. 11. Approximation of the bending moments BMat:

$$
V=20 \mathrm{kn} ., b=0^{\circ}, H_{S}=6 \mathrm{~m}, T_{S}=v a r
$$

\section{Identification}

In this part of the investigations was elaborated the artificial neural network which makes it possible to assess occurrence of the internal forces expressed in the form of the two-state function $\Omega_{\mathrm{S}}$ taking the values:

* ,1" - if values of internal forces do not exceed the criterion ones IF

* „, 0 - if values of internal forces exceed the criterion ones $\mathrm{IF}_{\text {crit }}$

As the criterion $\mathrm{IF}_{\text {crit. }}$ for internal forces of the ship in irregular waves were assumed the permissible still water internal forces $\mathrm{IF}_{\text {s.w.rit }}$ for B-517 bulk carrier, lessened by instantaneous values of the still water internal forces $\mathrm{IF}_{\text {s.w. }}$ of the ship in ballast loading condition, i.e:

$$
\mathrm{IF}_{\text {crit }}=\mathrm{IF}_{\text {s.w.crit. }}-\mathrm{IF}_{\text {s.w }}
$$

where:

$\mathrm{IF}_{\text {crit }} \quad$ - permissible internal force for ship in irregular waves

$\mathrm{IF}_{\text {s.w.crit. }}-$ permissible internal force for ship in still water (harbour state) taken from the ship's technical documentation

$\mathrm{IF}_{\text {s.w }}$ - calculated instantaneous value of still water internal force for ship in ballast loading condition.

The values of the still water internal forces were calculated with the use of the author's computer program Kalkulator. The instantaneous values of still water internal forces, permissible values of internal forces both in still water and irregular waves, are presented in Tab. 5 and 6.

Tab. 5. Values of shear forces of B-517 bulk carrier, at selected frame stations

\begin{tabular}{|c|c|c|c|}
\hline $\begin{array}{c}\text { Frame } \\
\text { station }\end{array}$ & $\begin{array}{c}\text { Instantaneous } \\
\text { value in still } \\
\text { water [kN] }\end{array}$ & $\begin{array}{c}\text { Permissible } \\
\text { value in still } \\
\text { water [kN] }\end{array}$ & $\begin{array}{c}\text { Permissible value } \\
\text { in irregular } \\
\text { waves [kN] }\end{array}$ \\
\hline 41 & 17678 & 43262 & 25584 \\
\hline 59 & 18237 & 48667 & 30431 \\
\hline 90 & 10987 & 48667 & 37680 \\
\hline 109 & 9261 & 48667 & 39407 \\
\hline 128 & 8888 & 48667 & 39780 \\
\hline 149 & 3698 & 48667 & 44969 \\
\hline 178 & 3640 & 60812 & 57173 \\
\hline
\end{tabular}

Tab.6. Values of bending moments of B-517 bulk carrier, at selected frame stations

\begin{tabular}{|c|c|c|c|}
\hline $\begin{array}{c}\text { Frame } \\
\text { station }\end{array}$ & $\begin{array}{c}\text { Instantaneous } \\
\text { value in still } \\
\text { water [kN] }\end{array}$ & $\begin{array}{c}\text { Permissible } \\
\text { value in still } \\
\text { water [kN] }\end{array}$ & $\begin{array}{c}\text { Permissible value } \\
\text { in irregular } \\
\text { waves [kN] }\end{array}$ \\
\hline 41 & 67042 & 1471500 & 1404458 \\
\hline 59 & 256198 & 1471500 & 1215302 \\
\hline 90 & 456106 & 1471500 & 1015394 \\
\hline 109 & 507354 & 1471500 & 964146 \\
\hline 128 & 543111 & 1471500 & 928389 \\
\hline 149 & 531996 & 1471500 & 939504 \\
\hline 178 & 361773 & 1471500 & 1109727 \\
\hline
\end{tabular}

The best artificial neural network which made it possible to assess values of internal forces, appeared the MLP network of $4 \times 13 \times 1$ structure, characterized by the statistics shown in Tab. 7. 
Tab. 7. Statistics applied to classification problems of the artificial neural network predicting values of the function $\Omega_{I F}$ for $B-517$ bulk carrier in ballast loading condition

\begin{tabular}{|c|c|c|c|c|c|c|}
\hline \multirow{2}{*}{$\begin{array}{c}\text { Number } \\
\text { of events }\end{array}$} & \multicolumn{2}{|c|}{ Teaching set } & \multicolumn{2}{c|}{$\begin{array}{c}\text { Validating } \\
\text { set }\end{array}$} & \multicolumn{2}{c|}{ Testing set } \\
\cline { 2 - 7 } & $\mathbf{\Omega}_{\mathrm{IF}}=\mathbf{0}$ & $\mathbf{\Omega}_{\mathrm{IF}}=\mathbf{1}$ & $\mathbf{\Omega}_{\mathrm{IF}}=\mathbf{0}$ & $\mathbf{\Omega}_{\mathrm{IF}}=\mathbf{1}$ & $\mathbf{\Omega}_{\mathrm{IF}}=\mathbf{0}$ & $\mathbf{\Omega}_{\mathrm{IF}}=\mathbf{1}$ \\
\hline Total & 100 & 1100 & 109 & 1091 & 6 & 58 \\
\hline Correct & 98 & 1086 & 108 & 1070 & 6 & 58 \\
\hline Erronous & 2 & 14 & 1 & 21 & 0 & 0 \\
\hline Indeterminate & 0 & 0 & 0 & 0 & 0 & 0 \\
\hline
\end{tabular}

The above given artificial neural network can be presented by means of Eq. (10):

$\Omega_{\mathrm{IF}}=\left(1+\exp \left(-\left(\frac{1}{1+\mathrm{e}^{\left.-\left(\left[\beta, \mathrm{V}, \mathrm{Hs}, \mathrm{T}_{\mathrm{S}}\right] \times \mathrm{S}+\mathrm{P}\right) \times \mathrm{A}-\mathrm{B}\right)}} \times \mathrm{C}-13.4\right)\right)\right)^{-1}$

where:

$\Omega_{\mathrm{IF}}-$ internal forces in the form of the following two-state nominal variable:

- „1" - if values of internal forces do not exceed the criterion ones

- „0" - if values of internal forces exceed the criterion ones

$\mathrm{V}-$ ship speed $[\mathrm{kn}]$

$\beta-$ wave encounter angle [deg]

$\mathrm{T}_{\mathrm{S}}-$ characteristic wave period [s]

$\mathrm{H}_{\mathrm{S}}-$ significant wave height $[\mathrm{m}]$.

$\mathrm{S}$ - matrix of coefficients having the same values as in Eq. (4)

$\mathrm{P}$ - vector of displacements having the same values as in Eq. (4).

\section{COMPARATIVE ANALYSIS OF APPROXIMATION AND IDENTIFICATION OF SEA-KEEPING QUALITIES}

In this part of investigations was performed the comparative analysis of approximation and identification accuracy of the elaborated neural networks for ship speed values beyond the range of those assumed for building the networks.

The tests were carried out on the basis of the following set of input parameters:

* the ship's speed $\mathrm{V}=20$ knots

* the wave encounter angle $\beta=0^{\circ}$ (following waves), $15^{\circ}$, $30^{\circ}, 60^{\circ}, 75^{\circ}, 90^{\circ}, 105^{\circ}, 120^{\circ}, 150^{\circ}, 175^{\circ}, 180^{\circ}$ (heading waves)
- the significant wave height $\mathrm{H}_{\mathrm{s}}$ ranging from 1 to $9 \mathrm{~m}$, taken every second $m$

* the characteristic wave period $\mathrm{T}_{\mathrm{s}}$ ranging from 6 to 20 $\mathrm{s}$, taken every second $\mathrm{s}$ the set contained 616 cases altogether.

Next, making use of the algorithms no. 1 and 2 as well as the elaborated neural networks one determined values of the function $\Omega$ for each case contained in the above mentioned set. In Tab. 8 are presented the numbers of correct and erroneous classifications in relation to model values of the function $\Omega$, and in Fig. 12 - the percentage specification of correct classifications

Tab. 8. Numbers of correct and erroneous classifications for the testing set identifying values of the function $\Omega$

\begin{tabular}{|c|c|c|c|c|}
\cline { 2 - 5 } \multicolumn{1}{c|}{} & \multicolumn{2}{c|}{ Correct classifications } & \multicolumn{2}{c|}{$\begin{array}{c}\text { Erroneous } \\
\text { classifications }\end{array}$} \\
\cline { 2 - 5 } & $\begin{array}{c}\text { Algorithm } \\
\text { no. 1 }\end{array}$ & $\begin{array}{c}\text { Algorithm } \\
\text { no. 2 }\end{array}$ & $\begin{array}{c}\text { Algorithm } \\
\text { no. 1 }\end{array}$ & $\begin{array}{c}\text { Algorithm } \\
\text { no. 2 }\end{array}$ \\
\hline $\begin{array}{c}\text { Additional } \\
\text { resistance }\end{array}$ & 300 & 494 & 316 & 122 \\
\hline Slamming & 587 & 605 & 29 & 11 \\
\hline $\begin{array}{c}\text { Internal } \\
\text { forces }\end{array}$ & 507 & 533 & 109 & 83 \\
\hline
\end{tabular}

From Tab. 8 and Fig. 12 it results that the elaborated artificial networks have relatively good extrapolating properties for the investigated range of data. Moreover it turned out that the application of algorithm no. 2 for determining values of the function $\Omega$ gives more exact solution. It may result from that

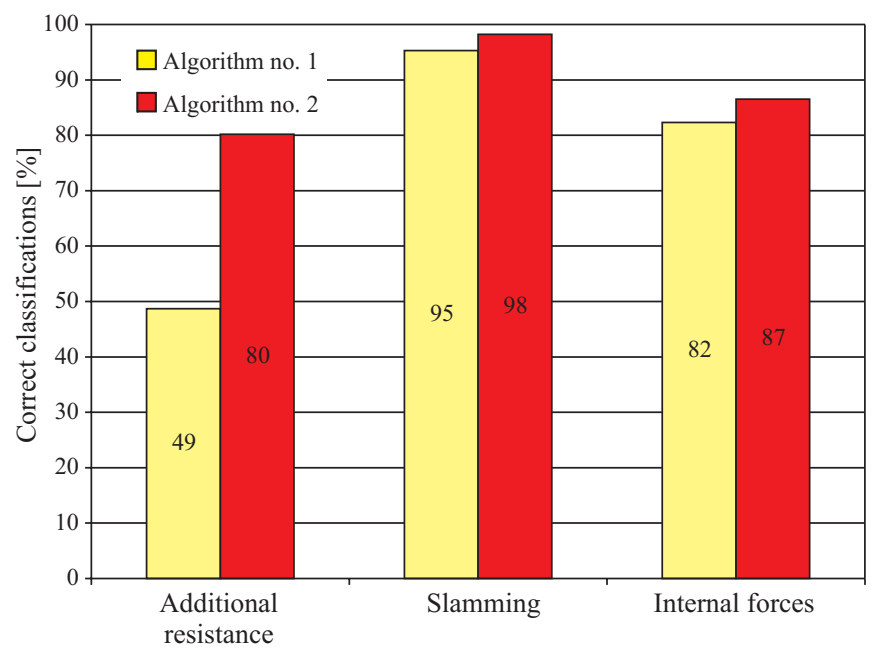

Fig. 12. Percentage specification of correct classifications

A - matrix of weighting values:

\begin{tabular}{|cccccccccccccc}
0.738 & -1.339 & 2.036 & 2.076 & 26.157 & 0.773 & -7.942 & -4.118 & -9.894 & -7.184 & -1.009 & -7.160 & -6.680 \\
2.190 & -1.415 & -6.310 & 0.941 & -0.995 & 0.584 & -2.556 & 0.355 & 0.785 & -10.104 & -3.078 & 0.785 & -3.075 \\
2.194 & -2.695 & 1.947 & -6.437 & -0.925 & 1.667 & -7.545 & -1.524 & 1.468 & -1.545 & -12.164 & 2.023 & 1.068 \\
6.907 & -1.163 & 2.876 & -6.349 & 8.502 & 1.077 & -17.785 & 0.998 & 12.706 & 2.509 & 16.332 & -0.846 & 1.631
\end{tabular} \mid

$B$ - vector of threshold values:

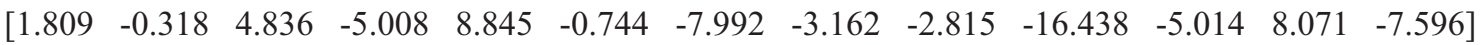

C - column vector of weighting values:

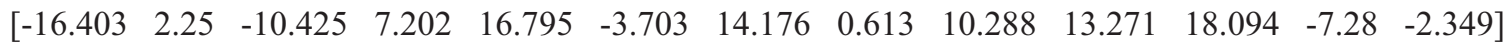


the accuracy of approximation or extrapolation is influenced by the range of input data which is rather narrow in the case of the function $\Omega$. When the function $\Omega$ is two-state one the accuracy of both the tested algorithms is close to each other (with outnumbering algorithm no. 2). And, when the function $\Omega$ is multi-state one (four-state one in the case of additional resistance) the accuracy of algorithm no. 2 greatly increases.

\section{SUMMARY}

In this work were elaborated the artificial neural networks which make it possible to approximate and identify selected sea-keeping qualities of B-B17 bulk carrier in ballast loading condition. The analysis was focused on:

- additional wave-generated resistance

- slamming

- shear forces and bending moments at selected frame stations depending on ship's motion and wave parameters.

The elaborated artificial neural networks were characterized by high accuracy within a wide range of values of ship motion and wave parameters.

The undertaken investigations were mainly aimed at making comparison of approximation and identification possibilities of artificial neural networks in assessing sea-keeping qualities. It turned out that more exact solutions were achieved by using the neural networks for identification of sea-keeping qualities. Such approach may find application in determining the operational effectiveness index $\mathrm{E}_{\mathrm{T}}$ given by Eq. (1) in the case of problems associated with ship design and operation.

\section{BIBLIOGRAPHY}

1. Karppinen T.: Criteria for Seakeeping Performance Predictions, ESPOO 1987

2. Journée J.M.J.: Verification and Validation of Ship Motions. Program SEAWAY, Report1213a, Delft University of Technology, The Netherlands, 2001

3. Journée J.M.J.: Theoretical Manual of SEAWAY, Report1216a, Delft University of Technology, The Netherlands, 2001

4. Szelangiewicz T.: Ship's Operational Effectiveness Factor as Criterion for Cargo Ship Design Estimation, Marine Technology Transaction, Polish Academy of Sciences, Branch in Gdańsk, Vol. 11, 2000.

\section{CONTACT WITH THE AUTHOR \\ Tomasz Cepowski, D.Sc.,Eng. Institute of Marine Navigation, Maritime University of Szczecin Wały Chrobrego $1 / 2$ \\ 70-500 Szczecin, POLAND e-mail : cepowski@am.szczecin.pl}

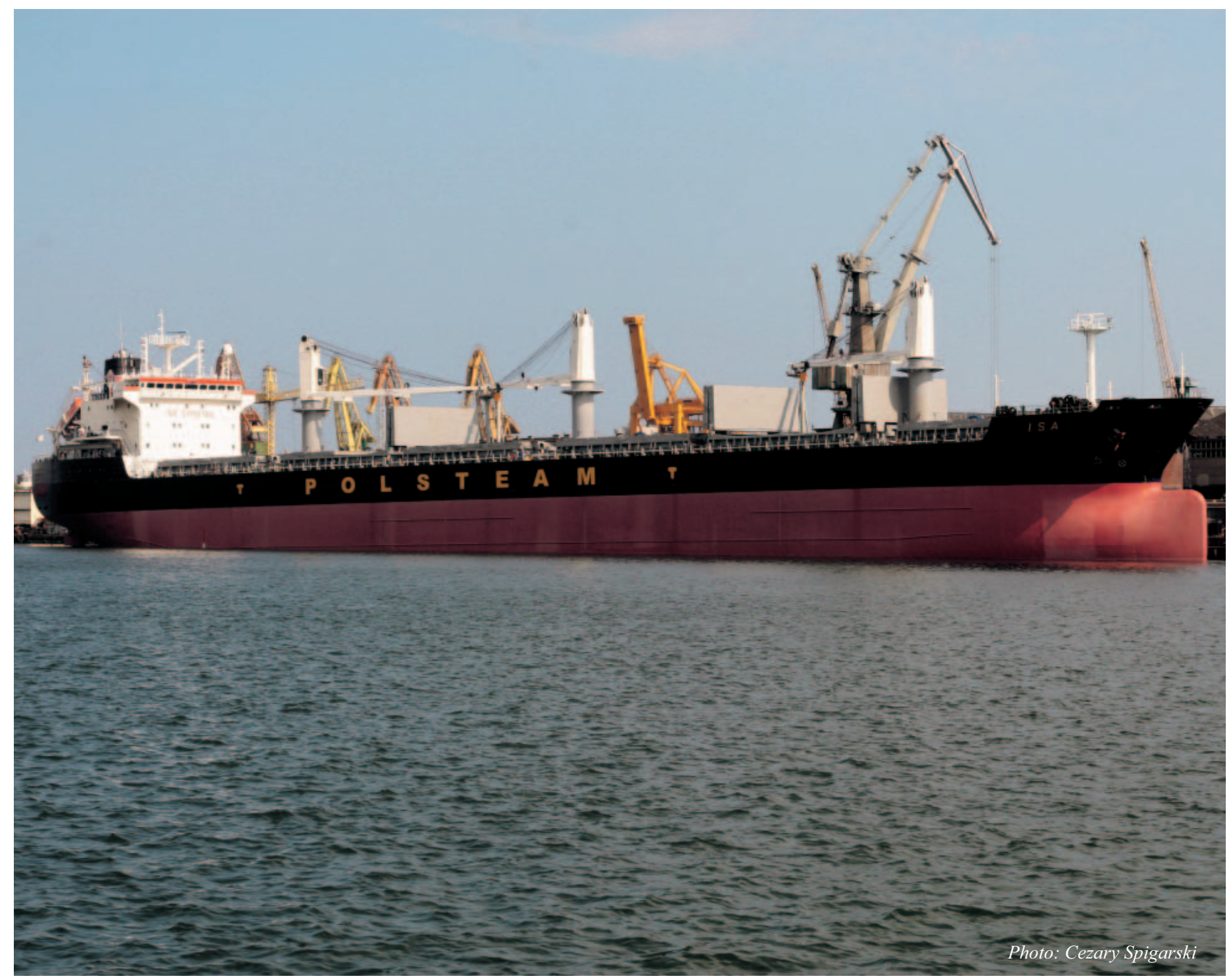

